\title{
Interparticle Neck Connections in Innovative Insulated Iron Powder Compounds
}

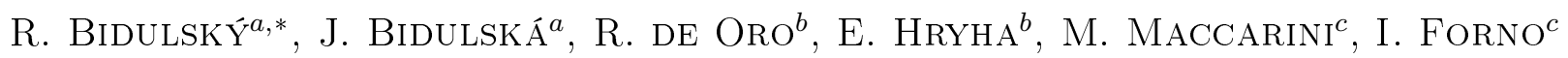 \\ AND M. ACTIS GRANDE ${ }^{d}$ \\ ${ }^{a}$ Technical University of Košice, Faculty of Metallurgy, Department of Metals Forming, \\ Letná 9, 04200 Košice, Slovakia \\ ${ }^{b}$ Chalmers University of Technology, Department of Materials and Manufacturing Technology, \\ Rannvagen 2, 41296 Göteborg, Sweden \\ ${ }^{c}$ Consorzio Prometeo, Viale T. Michel 5, 15121 Alessandria, Italy \\ ${ }^{d}$ Politecnico di Torino, Department of Applied Science and Technology, \\ Viale T. Michel 5, 15121 Alessandria, Italy
}

\begin{abstract}
Goal of the present paper is the analysis of the interparticle neck connections in a system made of insulated iron powder compounds with different additions of an $\mathrm{Al}-\mathrm{Mg}-\mathrm{Si}-\mathrm{Cu}$ alloy $(0.25,0.5$ and $0.75 \mathrm{wt} \%$ ). The introduction of the aluminium alloy powder has been made in order to improve the mechanical properties, evaluated as the transverse rupture strength, without decreasing the magnetic properties (evaluated in terms of iron loss and coercivity force). The fracture analysis of investigated systems puts into evidence the breaking of interparticle neck connections. Heat treatment (at the temperature of $500{ }^{\circ} \mathrm{C}$ ) contributes to the early stages of interparticle neck developments. The chosen aluminium alloy presents a sort of pre-sintering behaviour at $500{ }^{\circ} \mathrm{C}$, with the possibility of mass-transport processes around the insulated iron powder compounds. The air heat treatment applied aims at providing an increase in the mechanical behaviour of the material, with a final good rigidity after the cooling process. Fracture surfaces and transverse rupture strength values show that, at $500 \mathrm{MPa}$, the strength and the area related to the inter-particle necks can be correlated to the occasional broken insulated point-to-point surfaces that hinder the development of inter-particles necks.
\end{abstract}

DOI: $10.12693 /$ APhysPolA.128.647

PACS: 75.50.--y, 81.20.Ev, 81.40.Np

\section{Introduction}

Iron insulated powder compounds (IIPC) represent a relatively new material to be used in electrical machines and further design, material and manufacturing development. According to [1], the application of insulated powders to form magnetic cores for electric motors operating at low frequencies met with limited success. Nowadays, a successful design requires new thinking, a laminated component that is replaced with an exact replica made of iron powder. The ideal soft magnetic material is an isotropic media with very high magnetic permeability, low coercivity and high saturation induction. In addition, the material should be easily shaped into 3D structures in order to fully take advantage of the material's isotropic nature [1-5]. Lemieux et al. [1] underline that for induction machines with very low air gaps, operating at regular power frequencies $(50-60 \mathrm{~Hz})$, and for highpower-density machines, the poor properties of powdered materials with high hysteresis losses are barely acceptable. In addition, their mechanical strength is very low (maximum $100 \mathrm{MPa}$ ). This issue severely limits their fields of application.

*corresponding author; e-mail: robert.bidulsky@tuke.sk
Results obtained in [6-9] show that a maximum temperature of about $500^{\circ} \mathrm{C}$ is compatible with the conservation of good magnetic properties of IIPC: the attention has then been devoted to select a material able to introduce mechanical advantages under heat treatment at the reported temperature. Different powders have been mixed, the insulated iron powder (IIPC) and an $\mathrm{Al}-\mathrm{Mg}-$ $\mathrm{Si}-\mathrm{Cu}$ alloy (as the additional element), this latter responsible for the more homogeneous microstructure and as a better plastically ability agent than matrix powder one. The details about the role of aluminium based alloy in iron based SMC on magnetic materials, as well as the comparison of the properties of investigated materials with original SMC are presented in [11].

Insulated iron powders tend to perform better than steel laminations at frequencies higher than $400 \mathrm{~Hz}[2,6,12]$. However, for low frequency $\mathrm{AC}$ soft magnetic applications, the materials must have high permeability, low core losses and acceptable mechanical strength to compete with steel laminated assemblies.

\section{Experimental conditions}

The IIPC material (Somaloy 1P 700, Höganäs AB) has been blended with different amounts of aluminium alloy (ready-to-press aluminium based powder Alumix 321: Al-0.95 wt\% $\mathrm{Mg}-0.49$ wt\% $\mathrm{Si}-0.21 \mathrm{wt} \% \mathrm{Cu}-0.07$ wt\% Fe-1.6 wt\% lubricant, Ecka Granules). The investigated systems are given in the Table. 
TABLE

The investigated systems.

\begin{tabular}{c|c}
\hline \hline System & Chemical composition \\
\hline A & IIPC $+0.25 \%$ Alumix 321 \\
B & IIPC $+0.5 \%$ Alumix 321 \\
C & IIPC $+0.75 \%$ Alumix 321
\end{tabular}

Powder mixtures (PM) were homogenized using a laboratory Turbula mixer for $20 \mathrm{~min}$. Specimens with a different green density obtained using a $2000 \mathrm{kN}$ hydraulic press, in a disc-shaped mould ( $\Phi 40 \mathrm{~mm})$ and unnotched impact energy $55 \times 10 \times 10 \mathrm{~mm}^{3}$ specimens applying a pressure in the range $200,300,400,500,600$ and $700 \mathrm{MPa}$. Thermal treatments in air at the maximum temperature of $500{ }^{\circ} \mathrm{C}$ for 30 min were carried out on the evaluated systems. The green compacts were weighed with an accuracy of $\pm 0.001 \mathrm{~g}$. The dimensions were measured with a micrometer calliper $( \pm 0.01 \mathrm{~mm})$. Densities were evaluated using the water displacement method (the Archimede principle), according to the ASTM B962-08 standard.

The three-point bending (transverse rupture strength, TRS) test is based on the deformation of the specimen by bending with slow force until the moment when material failure occurs in the area of tension/stress.

Surface chemical analysis of the powder surface was performed by means of X-ray photoelectron spectroscopy using a PHI 5500 instrument. X-ray photoelectron spectroscopy was used in order to identify elements, present on the powder surface, together with their chemical state. The analyzed area during XPS analysis was about $0.8 \mathrm{~mm}$ in diameter and thus a large number of particles (more than 100 particles) was analyzed at the same time giving a statistically reliable average result that represents the general powder surface composition. Determination of the surface oxide layer thickness and compositional profiles was done by altering of ion etching and XPS analysis. The ion etching was performed by $\mathrm{Ar}^{+}$gas with an accelerating voltage of $4 \mathrm{kV}$ to the depths of 1 , 16 and $50 \mathrm{~nm}$. The $\mathrm{Ar}^{+}$beam was rastered on the area from $4 \times 5 \mathrm{~mm}^{2}$ with an etching rate of $25 \mathrm{~nm} \mathrm{~min}^{-1}$.

Fracture surfaces were investigated by means of SEM JEOL 7000F.

\section{Results and discussion}

The existence of free internal surfaces in sintered microstructure, such as pores and/or particle connections, results in several specific failure mechanisms. The fracture surfaces of PM materials are different from those observed on specimens made by other processes due to the interior pore surfaces. Some authors documented [13-15] that the fraction of pore edges, which appear as smooth free particle surfaces, varies with density, where lowdensity regions display large amounts of these free surfaces. In a highly porous and sufficiently plastic matrix, the basic failure mechanism is the interparticle ductile fracture. A distinct case of interparticle failure is the separation along the original particle surfaces without or with only minimal local plastic flow [13]. The presence of oxides along the grain boundaries in particle connections results in an interparticle intergranular failure. Transparticle transgranular ductile failure of sintered microstructure occurs only in the case of a low-porous and highplastic matrix. When transgranular cleavage fracture develops in sintered steels it has a transparticle character. In a highly porous microstructure it may transform into interparticle ductile failure [15].

As shown in Figs. 1-3, a low level of sinter necks was reached after heat treatment. There was no evidence of major plastic strains at the interparticle necks.

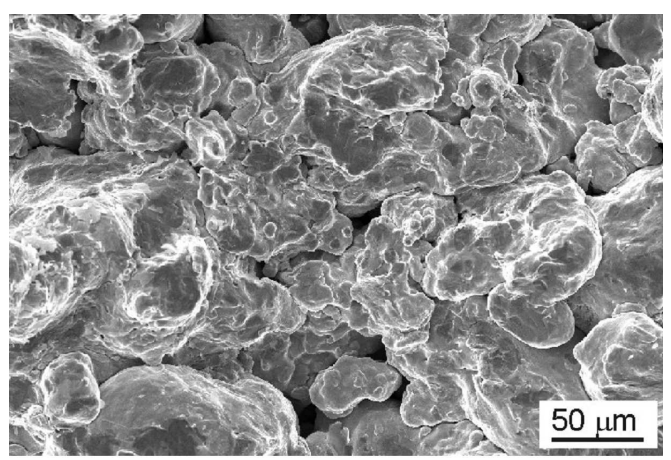

Fig. 1. Fracture surface of system A.

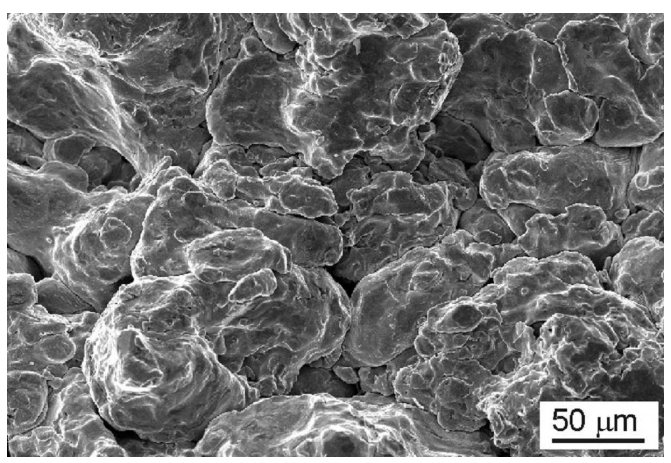

Fig. 2. Fracture surface of system B.

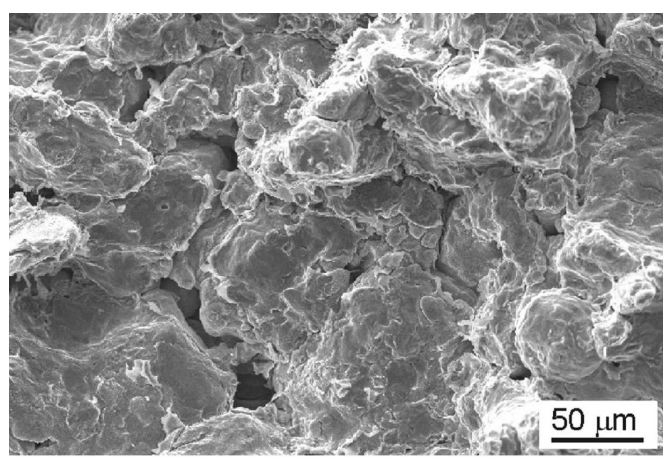

Fig. 3. Fracture surface of system C. 
In addition, well-defined insulated surfaces were present in the systems close to the areas where secondary porosity was present.

Strength properties, evaluated in terms of TRS values, are reported in the following Fig. 4.

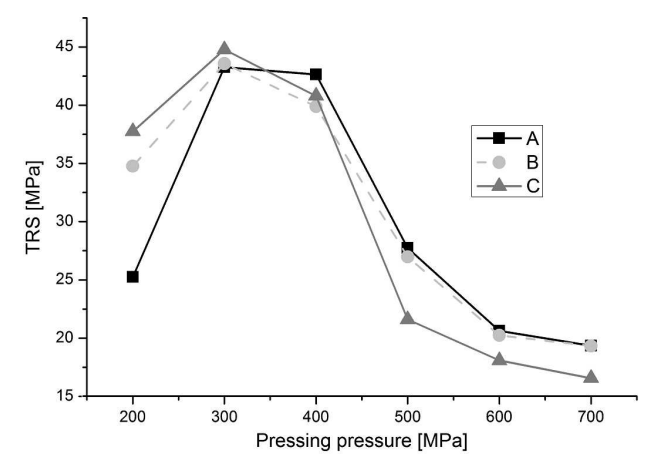

Fig. 4. Strength properties represent by TRS values in $\mathrm{MPa}$.

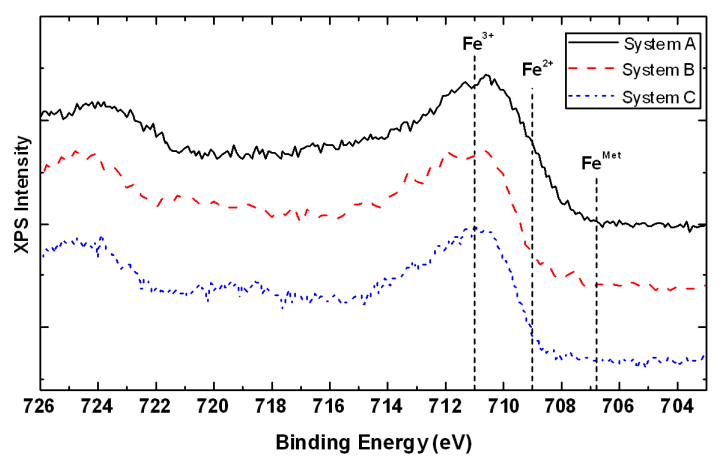

Fig. 5. Iron signal acquired with XPS from the fracture surfaces of systems A, B and C at $500 \mathrm{MPa}$.

Some bonds were created during heat treatment. These bonds are formed by thermal oxidation during the heat treatment. It is well known that heat treatment has to develop interparticle bonds, homogeneous distribution of aluminium alloying elements, and a reduction in porosity. Heat treatment (at the temperature of $500{ }^{\circ} \mathrm{C}$ ) contributes to the early stages of interparticle neck developments. According to $[16,17]$ this phenomenon revealed that interparticle oxide bonds formed during a heat treatment at moderate temperature lead to cohesive bonds between iron particles. The breaking points, in terms of strength loss at $300 \mathrm{MPa}$, are confirmed by the fracture analysis of investigated systems as well as X-ray photoelectron spectroscopy (XPS) analysis. Figure 5 shows that the fracture surface is completely covered by oxides where the main contribution comes from $\mathrm{Fe}^{3+}$.

Figures 6-8 present the apparent atomic concentration at different etching depths. It can be seen that the main elements are $\mathrm{Fe}$ and $\mathrm{O}$. Phosphorous profile is almost identical for the three samples and no aluminium was detected in any of the fracture surfaces, at least with the etching depth that was used. Also, the oxygen content seems to increase from system A to system C.

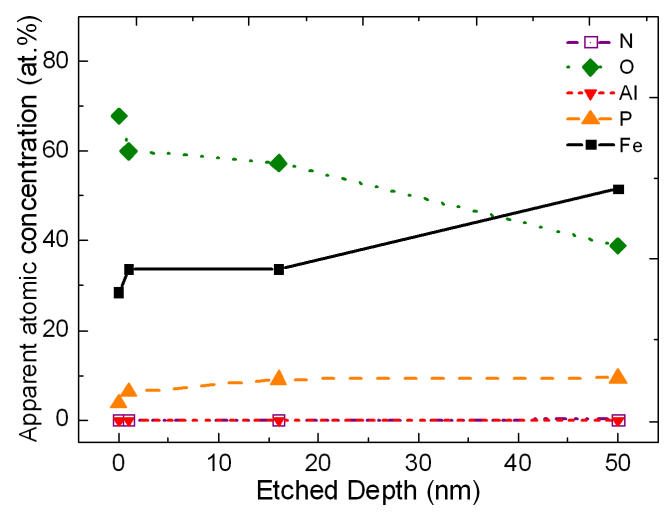

Fig. 6. Apparent atomic concentration profiles of the fracture surfaces of systems A at $500 \mathrm{MPa}$.

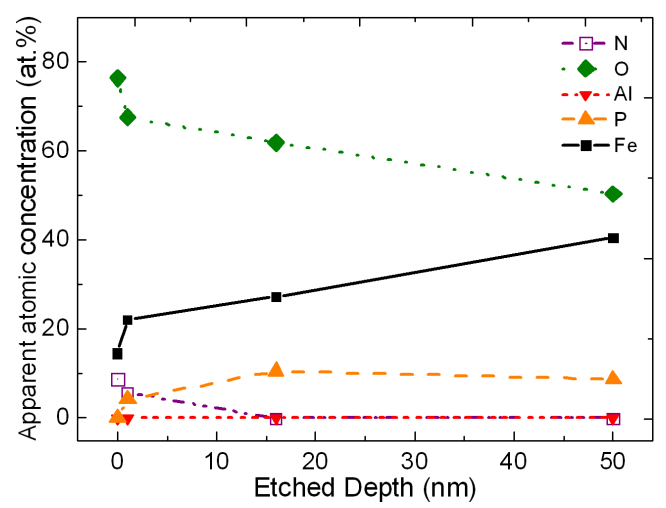

Fig. 7. As in Fig. 6, but for systems B at $500 \mathrm{MPa}$.

The chosen aluminium alloy presents a sort of presintering behaviour at $500{ }^{\circ} \mathrm{C}$, with the possibility of mass-transport processes around the insulated iron particles, whereas the air heat treatment applied aims at providing an increase in the mechanical behaviour of the material, with a final good rigidity after the cooling process.

Fracture surfaces and TRS values show that, at $300 \mathrm{MPa}$, the strength and the area related to the interparticle necks can be correlated to the occasional broken insulated point-to-point surfaces that hinder the development of interparticles necks.

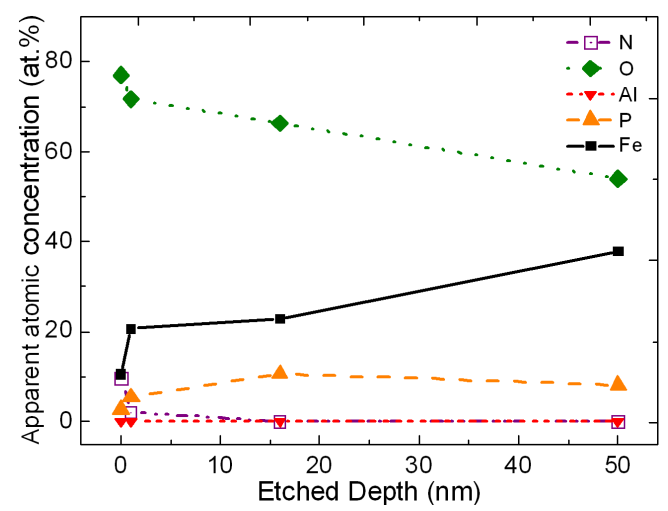

Fig. 8. As in Fig. 6, but for systems $\mathrm{C}$ at $500 \mathrm{MPa}$. 


\section{Conclusions}

1. The strength properties of new investigated systems depend on the occasional broken insulated point-to-point surfaces.

2. In terms of fracture, a low level of sinter necks was determined. There was no evidence of major plastic strains at the interparticle necks.

3. Present results, for low frequency AC soft magnetic applications, shows possibility of an $\mathrm{Al}-\mathrm{Mg}-\mathrm{Si}-\mathrm{Cu}$ alloy as the new additional element to the IIPC.

\section{Acknowledgments}

This work was realized within the frame of the Operational Program Research and Development: "The centre of competence for industrial research and development in the field of light metals and composites", project code ITMS: 26220220154 and financially supported by a European Regional Development Fund.

\section{References}

[1] P. Lemieux, R. Guthrie, M. Isac, JOM 64, 374 (2012).

[2] H. Shokrollahi, K. Janghorban, J. Mater. Process. Technol. 189, 1 (2007).

[3] C. Gélinas, D. Brydges, SAE Techn. Pap. 2003-010447, (2003).

[4] D. Olekšáková, J. Füzer, P. Kollár, S. Roth, J. Magn. Magn. Mater. 333, 18 (2013).
[5] C. Oikonomou, E. Hryha, L. Nyborg, Surf. Interface Anal. 44, 1166 (2012).

[6] R. Bidulský, M. Actis Grande, L. Ferraris, P. Ferraris, J. Bidulská, Acta Phys. Pol. A 118, 802 (2010).

[7] I.P. Gilbert, V. Moorthy, S.J. Bull, J.T. Evans, A.G. Jack, J. Magn. Magn. Mater. 242-245, 232 (2002).

[8] R. Bidulský, J. Bidulská, M. Actis Grande, L. Ferraris, Acta Metall. Slovaca 20, 271 (2014).

[9] R. Bidulský, M. Actis Grande, L. Ferraris, J. Bidulská, J. Optoelectron. Adv. Mater. 12, 1356 (2010).

[10] J. Bidulská, R. Kočiško, R. Bidulský, M.A. Grande, T. Donič, M. Martikán, Acta Metall. Slovaca 16, 4 (2010).

[11] M. Actis Grande, R. Bidulsky, A. Cavagnino, L. Ferraris, P. Ferraris, IEEE Trans. Ind. Appl. 48, 1335 (2012).

[12] A.G. Jack, B.C. Mecrow, P.G. Dickinson, D. Stephenson, J.S. Burdess, N. Fawcett, J.T. Evans, IEEE Trans. Ind. Appl. 36, 1077 (2000).

[13] E. Dudrova, M. Kabatova, R. Bidulsky, RoPM 2005, Vol. 1, TU, Cluj-Napoca, 2005, p. 101.

[14] T.F. Murphy, B. Lindsley, Adv. Powder Metall. Particul. Mater. 2, 11 (2007).

[15] E. Dudrova, M. Kabatova, Powder Metall. Progr. 8, 59 (2008).

[16] T. Werber, in: Non-Stoichiometric Compounds Surfaces, Grain Boundaries and Structural Defects, Eds. J. Nowotny, W. Weppner, 1989, p. 547.

[17] L.P. Lefebvre, S. Pelletier, C. Gélinas, Adv. Powder Metall. Particul. Mater. 8, 47 (1998). 